\title{
Features and Trends of Social Sciences Applied to Sport in the Italian Context
}

\author{
Irene Strazzeri' and Giusi Antonia Toto' \\ 'University of Foggia, Department of Humanistic studies, Foggia, Italy
}

\begin{abstract}
In Italy, initially the social sciences of Sport was considered a specialization to the macro-discipline of Sociology of leisure time, but today it boasts a tradition of pluriventennial studies. It is equally important to consider the number of this discipline among the studies on mass culture due to its extent of aggregating phenomenon. The purpose of this article is to examine the research trends of social sciences applied to sport in the Italian context. From a methodological point of view, a systematic review of the existing literature will be provided following the PRISMA guidelines both on the main research currents and on the main emerging topics in the contemporary specialist literature. Comparing application studies and empirical experiences, it can be suggested that the social sciences in Italy with an international scientific tradition play a key role in research applied to sports by specializing research tendencies towards specific topics of study.
\end{abstract}

Key words: sport, sport science, psychology of sport, sociology of sport, physical education

\section{Introduction}

Sociological research in this field has had a substantial quantitative development, made possible by the transition of theories, models and constructs of the social sciences to this unprecedented field of knowledge (Porro, 2001). The main approaches that sport sociologists have followed in contemporary research trends have been: structural-functionalist theory, conflict theory, symbolic interactionism and historical sociology.

Functionalism considers society as an organic system characterized by the function of the production process, in which inputs enter this process to generate outputs released into the environment, sometimes through a circular logic. The survival of this system is linked to the satisfaction of four fundamental functions: the function of preservation of the latent model (1), that is the maintenance of one's own identity over time and with respect to the surrounding environment; the function of integration (2) between the parties, regulated by a system of rules that direct the internal flow; the function of achieving the goal (3) that the system must pursue and, finally, the adap- tation function (4), ie how the system responds and organizes the stimuli coming from the environment. Each social system is organized into subsystems that perform these four functions, for example, the family or school perform the function of preservation of the latent model. This theory was simplified in Merton's structural-functionalism model (1968); with respect to the rigidity of the subsystems the distinction was introduced in the systems between latent and manifest functions and between functions and dysfunctions, thus creating the possibility of conflicts within the systems themselves. For structural-functionalism, society is governed both by shared values and by institutions that maintain social order.

According to the (functionalist) theory of conflict, social relations are built from conflicts, in fact, the parties involved are involved in an intense interaction in which each is influenced by the actions of the other. Conflict strengthens identity between conflicting groups and creates strong bonds of intra-group solidarity. In order to neutralize internal conflicts within groups it can be effective not to destroy an external adversary whose presence strengthens internal bonds. The presence of conflicts allows to create rules of action that limit

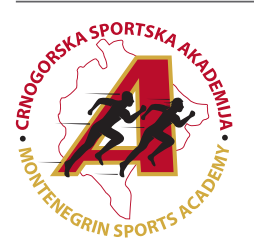

Correspondence:

G. A. Toto

University of Foggia, Department of Humanistic studies, Foggia, Italy

E-mail: giusy.toto@unifg.it 
intrinsic destructiveness and produces the search for group alliances. In a less optimistic perspective (Kriesberg, 1982) the conflict is characterized by processes of escalation and de-escalation that lead, respectively, to the elimination of the contenders or to the resolution through compromises.

Symbolic interactionism identifies social interactions built by individuals as symbolic and meaning guides in human actions. Therefore, reality is not a passive environment of adaptation, but the product of a continuous social construction. Within the socially constructed vital worlds, interactionists identify in the construct of identity the interpretative unity of all the attributions of meaning of the society in which it is positioned. Gender, political, ethnic or religious identities are continually constructed and reconstructed in relation to situations or other collective identities.

Elias (1987), one of the leading historians of historical sociology, asserts that long-term historical processes can explain the evolution of contemporary societies; individuals are interconnected through social apparatus (figurations) that create mutual dependencies and groups. The study of society, in this perspective, passes through the comparative study of social figures and their historical evolution. Figurations recognize the social value of emotions and the need to rationalize and control them within a process of civilization. At the macro-social level the process of civilization is the plurisecular effort of societies to channel conflicts and violence

\section{Methods}

A systematic review of the existing literature was adopted to search for articles in the main international databases (Google Scholar, PsycInfo and Scopus) on the issue in the research of social sciences applied to sport in the Italian context, using, in English and in Italian, just the terms "Sport", "Sport Scien- ce", "Psychology of sport", "Sociology of sport" and "Physical education" as keywords. Following the Prisma guidelines (Moher, Liberati, Tetzlaff, \& Altman, 2009) a systematic literature review process has been conducted: the literature search is followed by an evaluation of the titles and abstracts based on the research idea that the social sciences in Italy with an international scientific tradition play a key role in research applied to sports by specializing research tendencies towards specific topics of study (identification) (Toto \& Strazzeri, 2018). Bibliographic research and evaluation for the inclusion of publications was conducted independently by the two authors. The disagreements have been solved through a critical discussion, coming to full agreement between them. Regarding the inclusion and exclusion criteria, articles were selected in peer reviewed journals, books or book chapters in English or Italian that aimed to describe or evaluate the dimensions and variables expressed in the above-mentioned research idea (screening). All publications that dealt with addiction only in general, and those publications whose complete format (Relevance) could not be found were excluded. The time limit for the year of publication has been set for the last 10 years, so the articles have been selected since 2008. For the inclusion of the contributions, a qualitative summary of the most relevant information was also conducted with comparisons between the various publications without carrying out a quantitative analysis in the meta-analysis format. The process of inclusion of studies in the systematic review is described in Figure 1. After the elimination of duplicates, the research identified 1002 studies consistent with the research idea. Subsequently on the basis of the title and the abstracts, 547 studies were excluded because they were not relevant. Of the 455 with full text 374 studies met the inclusion criteria.

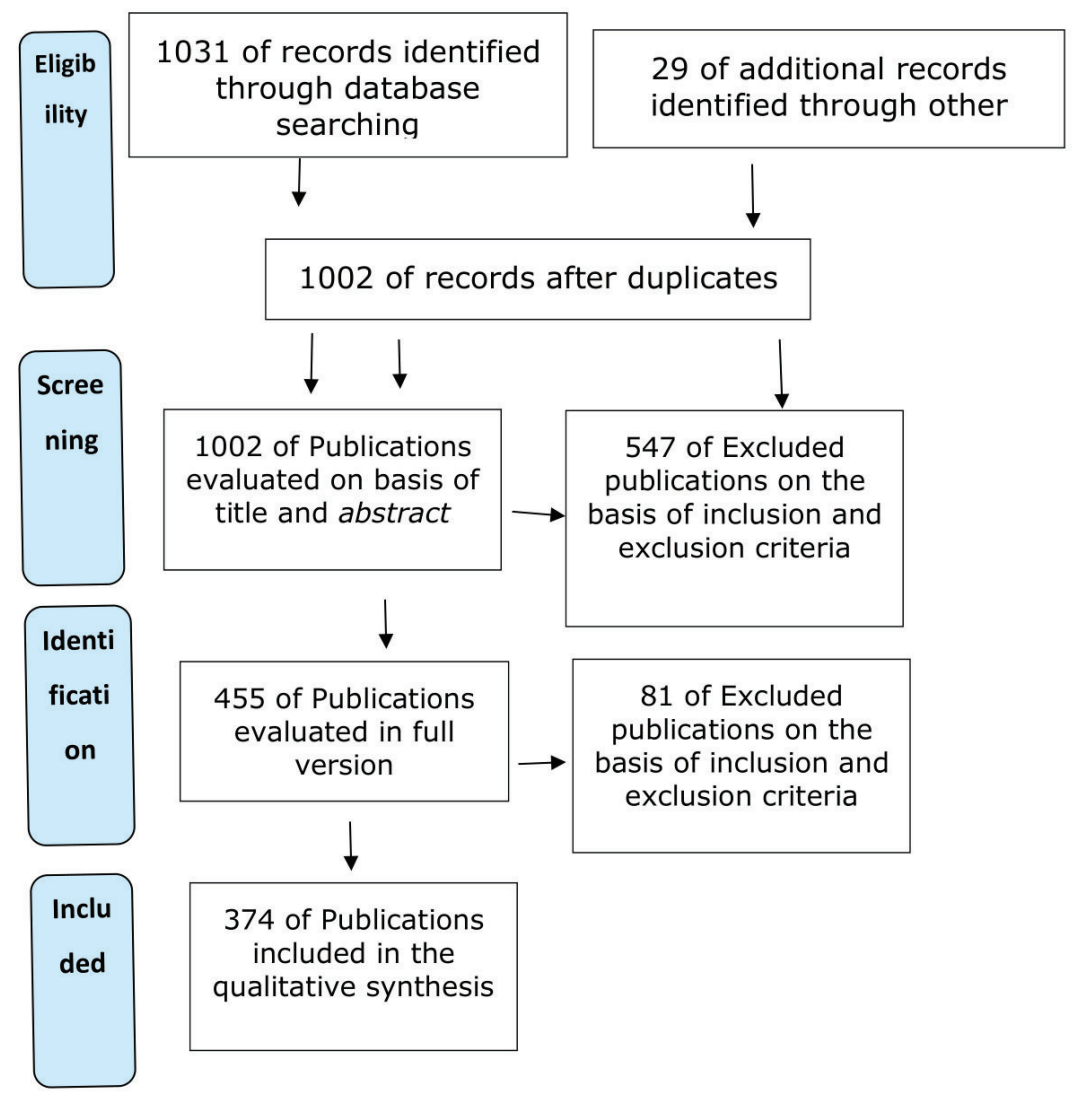

Figure 1. PRISMA Flow Chart of the selection process 


\section{Results}

This section presents the main contents of the literature on the topic. From this analysis emerge four main research strands (Table 1):

Table 1. Themes and number of publications

\begin{tabular}{cccc}
\hline $\begin{array}{c}\text { First theme of social science } \\
\text { in sport }\end{array}$ & Second Theme & Third Theme & Fourth Theme \\
\hline $\begin{array}{c}\text { Sportivisation process } \\
\text { Publication n. } 108\end{array}$ & Identity construction & Discrimination of gender or race & Political or religious ideology \\
\hline
\end{tabular}

Regarding the first theme, the process of sportivisation (1), a reflection of globalization, has profoundly changed the classic models of sport. The sporting process developed by the rationalization of popular pastimes leads to the transformation of sports activities in the modern sense. Contemporary competition has taken the forms of cosmopolitanism and rationalism so as to become an expression of struggle for the hegemony of subaltern cultures.

An important theme from a sociological point of view is the analysis of the identity structures (2) of sportsmen in contemporary society; the process of socialization through exchange with significant others creates personal identities (Toto, 2017a; Toto, Ruberto, \& Toto, 2018). The emergence of collective identities that are formed from social interactions that generate symbols and norms and from relationships aimed at achieving common objectives (Martelli \& Porro, 2013) is much more complex.

Even if the athletes are equal (3) the number of men in sports of excellence in all other fields of sport appears much lower, and this also occurs in Western countries (Dati Censis 2006, SIP Survey 2014). Gender and racial discrimination are extensively investigated in social science studies applied to sports. Political ideology (4) has had a close relationship with sport; politics in the history of the last century has manipulated sporting events to legitimize its being. The visibility of ideology is also the means by which political extremists use major sporting events for demonstration actions. From recent studies, it seems that both these two dimensions appear more attenuated in the third millennium, demonstrating a progressive autonomy of sport. Finally, the last area of major importance in social life is the intersection of sport with religion.

\section{Discussion}

Compared to the theories reported, the sociology of sport has applied generalist constructs to sports practice. Sport as an institution is a modern education evolved from complex cultural and social processes such as industrialization, urbanization, political revolutions, the importance of the market and the emergence of capitalism. Modernization has accelerated the process of developing social and cultural structures by producing profound changes. Since the 60 s of the last century, the global and mass media spread of sports has led to the emergence of new cultural partners in the world sports scene, establishing a shift in the sports center towards non-western countries. The tension to de-territorialisation will be an advantage in social terms, because it will produce an increase in creativity and expressiveness of sporting practice (Maguire, 2011).

Post-modern society, more than in the past, appears to be characterized by forms of control and encroachment of emotions, due to the limits and coercions of the high forms of rationalization of social action (Toto, 2017b). One of the few areas that escapes the control of rationalizing action is sport, or more generally the activities of free time, in which individuals can give free expression to emotions (cathartic action) and consequently succeed in balancing the coercive forces of the context post-modern social (compensatory action) (Dunning, 1990).

The sociologists starting from Elias (Elias, Dunning, Chicheportiche, Duvigneau, \& Chartier, 1998) saw in sport the instrument of channelling aggression following the acceptance by the populations of the monopoly of force by the States. And it is precisely within these dynamics of post-modern society that sport emerges as an institution. Even in sports, gender discrimination plays a significant role. The ideal model of a woman in modern society follows the canons of the "model" icon, far from the athletes' musculature and the typical values of sports. Through the lens of this prejudice we can read the interest of women in sports activities in terms of physicality statuary, never well-being or competitive competitiveness. The masculine sports ideology considers sport as competition, aggressiveness and supremacy over the adversary, in contrast to the female self-exclusion model from sporting activities (Strazzeri, 2016).

Another field of identity tension is the interaction between ethnic minorities; racism, an unresolved dynamic even in contemporary society, has exacerbated the conflicts produced by new forms of poverty and the economic crisis of the third millennium (Strazzeri \& Toto, 2017). Connected to the concept of race, racism indicates presumed superiority with respect to the characters transmitted through biological inheritance, which would determine human behavior. If in a post-modern society one race is superior to another, then even in sports, certain races would excel. Several studies show that it is not race that establishes success in sports, but the socio-cultural context of belonging that directs certain classes of individuals towards the practice of some sports, rather than others or to other types of activities (Groeneveld, Houlihan, \& Ohl, 2011). In this perspective the future research prospects direct the studies towards the functions of ethnic integration and social pacification that the sports take on, in fact, there are several examples of occasions for encounter between minors belonging to opposing ethnic groups, as a means of reconciliation as the case of the neighboring ex-Yugoslavia in the 1990s (Cavalli, 2016).

The advent of secularization in Europe has relegated the profession of religion to the private sphere and this appears to be in sharp contrast with the sport characterized, instead, by the values of the body and the public dimension of performance. In the first half of the twentieth century, Europe struggling with the struggles for totalitarianism and the clash between religion and atheism had charged the sport with meanings replacing religion to mobilize the masses (Martelli, 1999). In the contemporary context characterized by globalization, risk, change towards post-modernity, this opposition loses its meaning. The meeting, today, between sport and religion takes on 
many facets; this meeting is encouraged for athletes who can draw motivational motivation and resources to conduct correct behavior, both as an element aggregated in youth policies (Toto, 2018a).

\section{Acknowledgements}

There are no acknowledgements.

\section{Conflict of Interest}

The authors declare that there are no conflicts of interest.

Received: 14 October 2018 | Accepted: 12 December 2018 | Published: 01 February 2019

\section{References}

Cavalli, A. (2016). Incontro con la sociologia. II Mulino.

Dunning, E. (1990). Sociological reflections on sport, violence and civilization. International review for the sociology of sport, 25(1), 65-81.

Dati Censis (2006). Italy Today. Social picture and trends 2006. Franco Angeli

Elias, N., Dunning, E., Chicheportiche, J., Duvigneau, F., \& Chartier, R. (1998). Sport et civilisation: la violence maîtrisée. Fayard.

Elias, N. (1987). Die Gesellschaft der individuen, 10. Suhrkamp.

Groeneveld, M., Houlihan, B., \& Ohl, F. (Eds.). (2011). Social capital and sport governance in Europe. London: Routledge.

Kriesberg, L. (1982). Social conflicts. Prentice Hall.

Maguire, J.A. (2011). Power and global sport: Zones of prestige, emulation and resistance. Sport in Society, 14(7-8), 1010-1026.

Martelli, S. (1999). Sociologia dei processi culturali. Lineamenti e tendenze, La Scuola.

Martelli, S., \& Porro, N. (2013). Manuale di sociologia dello sport e dell'attività fisica. Franco Angeli.
Merton, R.K., \& Merton, R.K. (1968). Social theory and social structure. Simon and Schuster.

Moher, D., Liberati, A., Tetzlaff, J., Altman, D.G., \& Prisma Group. (2009). Preferred reporting items for systematic reviews and meta-analyses: the PRISMA statement. PLoS medicine, 6(7), e1000097.

Porro, N. (2001). Lineamenti di sociologia dello sport. Carocci.

SIP Survey (2014). Retrieved 12/09, 2018, from www.rcn.org.uk/newsevents/ hydrationhttps://www.thesipschool.com/files/TheSIPSurvey2014.pdf.

Strazzeri, I. (2016). La Resistenza della differenza. Tra liberazione e dominio. Mimesis.

Strazzeri, I., \& Toto, G.A. (2017). Globalization: Between Immigration and Discrimination, What Opportunities Emerge in this New Order? In the 30th International Business Information Management Association Conference-IBIMA (5185-5191).

Toto, G.A. (2017a). The influences of musical learning on psycho-physical development, intelligence and technology. The online journal of educational tecnology, 16(1), 604-610.

Toto, G.A. (2017b). The Role of The musical Learning in the Development of the socio and cognitive abilities. A review. The online journal of educational tecnology, 16(1), 801-807.

Toto, G.A. (2018). From Educational Contexts to Addictions: the Role of Technology in Teaching Methodologies and in Prevention as an Educational Function. Journal of e-Learing and Knowledge Society, 14(2), 203-212.

Toto, G., \& Strazzeri, I. (2018). Sport and physical education as prevention against technological addictions. Journal of Human Sport and Exercise, in press. doi:https://doi.org/10.14198/jhse.2019.141.11

Toto, G.A., Ruberto V., \& Toto M. (2018). Technologies: A Comparison between Negative Aspects of Addictions and Effects on Text Comprehension. In the 31th International Business Information Management Association Conference-IBIMA (6380-6390). 